\title{
Involvement of Large Plasma von Willebrand Factor (vWF) Multimers and Unusually Large vWF Forms Derived from Endothelial Cells in Shear Stress-induced Platelet Aggregation
}

\author{
Joel L. Moake, ${ }^{\ddagger}$ Nancy A. Turner, ${ }^{\star}$ Nikos A. Stathopoulos, ${ }^{\star}$ Leticia H. Nolasco, $¥$ and J. David Hellums*
}

*Rice University, $\ddagger$ Baylor College of Medicine, and $¥$ The Methodist Hospital, Houston, Texas 77030

\begin{abstract}
A fluid shear stress of $180 \mathrm{dyn} / \mathrm{cm}^{2}$ was applied for 0.5 and 5 min to platelets in citrated plasma or blood in a cone and plate viscometer with minimal platelet-surface interactions. Platelets aggregated in the shear field if large von Willebrand Factor (vWF) multimers were present. Aggregation did not require ristocetin, other exogenous agents, or desialation of vWF. Unusually large vWF multimers produced by human endothelial cells were functionally more effective than the largest plasma vWF forms in supporting shear-induced aggregation. Shear-induced aggregation was inhibited by monoclonal antibodies to platelet glycoprotein Ib or the IIb/IIIa complex, but was little affected by the absence of fibrinogen.

vWF-dependent platelet aggregation under elevated shear stress in partially occluded vessels of the arterial microcirculation may contribute to thrombosis, especially if unusually large vWF multimers are released locally from stimulated or disrupted endothelial cells.
\end{abstract}

\section{Introduction}

Fluid shear stress may reach levels of 200-400 dyn $/ \mathrm{cm}^{2}$ in small arteries and arterioles that are partially occluded, as by atherosclerosis or vascular spasm (1-3). Under these conditions, vessels of the microcirculation are subject to thrombotic occlusion by aggregated blood platelets $(3,4)$. Elevated levels of shear stress may have an important influence on pathological platelet clumping, especially since it is known that in vitro application of shear stress to platelets in normal plasma or whole blood can induce aggregation (5-12). The subject of this report is a more precise understanding of the mechanism responsible for the initiation of platelet aggregation in shear fields.

It has been proposed that ADP released from platelets is a mediator of shear-induced platelet aggregation in platelet-rich plasma (PRP) ${ }^{1}(10)$. Our previous studies (8) demonstrated that platelets, in citrated PRP exposed to controlled levels of shear stress up to $800 \mathrm{dyn} / \mathrm{cm}^{2}$ for $30 \mathrm{~s}$ at ambient temperature, release only $5-7 \%$ of the $\left[{ }^{14} \mathrm{C}\right]$ serotonin used as a marker for the release

Address correspondence to Dr. Moake, Medical Hematology Section, The Methodist Hospital, 6565 Fannin, MS 902 Main Bldg., Houston, TX 77030.

Received for publication 4 June 1986.

1. Abbreviations used in this paper: PPP, platelet-poor plasma; PRP, platelet-rich plasma; vWD, von Willebrand's disease; vWF, von Willebrand factor.

J. Clin. Invest.

(C) The American Society for Clinical Investigation, Inc.

0021-9738/86/12/1456/06 \$1.00

Volume 78, December 1986, 1456-1461 of dense granule contents (ADP, ATP, $\mathrm{Ca}^{2+}$ and other dense granule constituents). When PRP is sheared for $5 \mathrm{~min}$ at room temperature and $180 \mathrm{dyn} / \mathrm{cm}^{2}$, the extent of $\left[{ }^{14} \mathrm{C}\right]$ serotonin release reaches 25-30\% (with little detectable platelet lysis, based on lactic acid dehydrogenase measurements) (Peterson, D. M., N. A. Stathopoulos, T. D. Giorgio, J. D. Hellums, and J. L. Moake, manuscript submitted for publication). In citrated whole blood, shear stress levels of $\sim 100 \mathrm{dyn} / \mathrm{cm}^{2}$ produce platelet aggregates that may be stabilized by the relatively small quantities of ADP released from erythrocytes $(11,13)$ or platelets $(10)$.

Observations by other investigators (14) have implicated von Willebrand factor (vWF) in platelet thrombus formation, as well as in platelet-subendothelial interactions, in a flowing system. In a recent preliminary report, Joist et al. (15) presented evidence for defective shear-induced platelet aggregation in severe von Willebrand's disease (vWD) PRP. They interpreted their data as indicating diminished platelet-surface interactions in their couette rotational viscometer.

We have investigated the phenomenon of shear-induced platelet aggregation in citrated PRP and whole blood using a rotational viscometer with cone- and plate geometry. This instrument has important experimental advantages. It can apply uniform shear fields to test samples by generating specified shear rates within $1 \mathrm{~s}$ under conditions in which blood cell interactions with the viscometer surface have little influence on the experimental results $(7,8,12)$. Using this system to study the effects of viscoelastic forces on platelet aggregation, we have obtained evidence that $\mathrm{vWF}$ is involved in shear-induced platelet clumping. We find that the initiation of shear-induced platelet aggregation is dependent on large vWF multimeric forms. The addition of ristocetin, any other exogenous agonist, or chemical desialation of vWF multimers is not required.

The vWF multimers synthesized by megakaryocytes and packaged within platelet $\alpha$-granules, as well as the vWF multimers synthesized and packaged within endothelial cells, are comprised of all the vWF multimeric forms found in normal plasma. In addition, platelets and endothelial cells contain vWF forms even larger than those found in normal plasma ("unusually large" vWF multimers) (16). In our system, unusually large vWF multimeric forms derived from endothelial cells are exceptionally effective in supporting shear-induced platelet aggregation. Apparently, the role of platelet vWF multimers in this phenomenon is minimal. Our results indicate that unusually large vWF forms derived from endothelial cells are more efficient in interacting with platelets than the largest vWF forms present in normal plasma. This may have implications in both normal hemostasis and thrombosis.

\section{Methods}

Blood from normal healthy individuals not taking aspirin or any other medication was drawn into siliconized tubes containing $0.38 \%$ sodium 
citrate (final concentration) as anticoagulant. PRP was prepared by centrifugation of citrated whole blood at $150 \mathrm{~g}$ for $15 \mathrm{~min}$. In separating platelets from citrated whole blood, $\mathrm{PGI}_{2}$ was added in a final concentration at $10^{-8} \mathrm{M}$ to impede platelet aggregation and release during centrifugation and washing. Platelet pellets were either resuspended directly, or washed twice with Hepes buffer $(1.0 \mathrm{mM}$ Hepes, pH 74, $0.1 \mathrm{mM}$ $\mathrm{Ca}^{2+}, 1 \mathrm{mg} / \mathrm{ml}$ glucose, $3.5 \mathrm{mg} / \mathrm{ml}$ bovine serum albumin [BSA]) and then resuspended into an equal volume of autologous normal plateletpoor plasma (PPP), severe vWD PPP (containing $<1 \%$ vWF antigen and undetectable vWF multimers), or afibrinogenemic plasma (fibrinogen $<10 \mathrm{mg} / \mathrm{dl}$; purchased from George King Biomedical, Inc., Overland Park, KA). Before the shear experiments, the various platelet/plasma suspensions were incubated for $\sim 4 \mathrm{~h}$ at room temperature until the $\mathrm{PGI}_{2}$ inhibitory effect had dissipated and the platelets aggregated normally in response to ADP and collagen.

In experiments with whole blood the platelet/plasma suspensions were mixed with normal red blood cell/white blood cell suspensions that had been removed from PRP after the first centrifugation of whole blood.

Platelet and whole blood suspensions were subjected to controlled shear stress levels in a stainless steel cone and plate viscometer (Fig. 1; model 781; Ferranti Electric, Inc., Commack, NY) at $24^{\circ} \mathrm{C}(12) .0 .6-\mathrm{ml}$ samples were pipetted onto the platen surface of the viscometer and sheared at $180 \mathrm{dyn} / \mathrm{cm}^{2}$ for $30 \mathrm{~s}$ or $5 \mathrm{~min}$. After shearing, $10 \mu \mathrm{l}$ of the platelet samples and $3.3 \mu \mathrm{l}$ of the whole blood samples were dispensed in $20 \mathrm{ml}$ of Isoton II (Coulter Electronics, Inc., Hialeah, FL) diluent containing $0.5 \%$ glutaraldehyde. Particle count and size distribution were determined with an electronic particle counter (model ZBI with Channelyzer; Coulter Electronics, Inc.) using a sample volume of $100 \mu$ l for platelet/plasma and $500 \mu \mathrm{l}$ for whole blood, and a $50-\mu \mathrm{m}$-diameter aperture. Particles with sizes $\pm 20 \%$ of the mean platelet distribution in the unsheared samples were considered as single platelets. The disappearance of single platelets could be accounted for by the formation of platelet aggregates. Thus, the percent decrease in single platelets is directly related to the percent increase in platelet aggregates.

Purified murine monoclonal antibody 6D1 is directed against GPIb (17), whereas the 10E5 antibody is directed against GPIIb and/or GPIIIa (18). These were generously provided by Dr. Barry S. Coller of the State University of New York at Stony Brook. Some whole blood samples were incubated for $5 \mathrm{~min}$ before shearing with either $6 \mu \mathrm{g} / \mathrm{ml}$ of the $6 \mathrm{D} 1$ monoclonal antibody or $10 \mu \mathrm{g} / \mathrm{ml}$ of the $10 \mathrm{E} 5$ antibody.

vWF antigen levels in patient and normal plasma were quantified by solid-phase immunoradiometric assay (16). vWF multimers were separated by sodium dodecyl sulfate (SDS)-agarose gel electrophoresis, overlaid with rabbit ${ }^{125} \mathrm{I}$-antihuman $\mathrm{VWF}$ IgG, and analyzed by autoradiography using $1 \%$ agarose and a continuous buffer system (14). $1 \%$ agarose gel slabs, $1.5 \times 110 \times 230 \mathrm{~mm}$, were formed in the running buffer of $0.04 \mathrm{M}$ Tris-HCl/0.02 M sodium acetate/2 mM EDTA/0.1\% $\mathrm{SDS}, \mathrm{pH}$ 7.4. Samples were mixed with $0.02 \mathrm{M}$ Tris-HCl/2 mM EDTA/ $8 \mathrm{mM}$ urea/2\% SDS, pH 8.0 , and incubated at $60^{\circ} \mathrm{C}$ for $20 \mathrm{~min} .15 \mu \mathrm{l}$ was applied to the gel wells under a layer of running buffer. After elec-

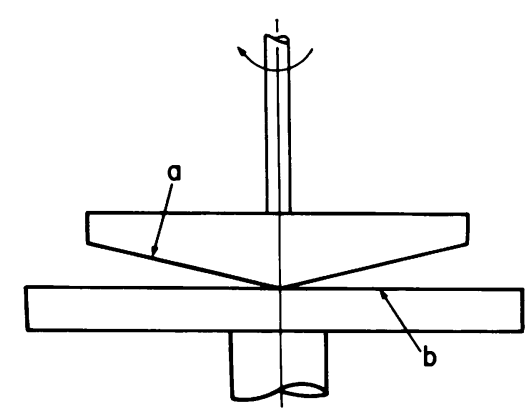

Figure 1. Cutaway view of the cone-plate viscometer showing $(a)$ the rotating cone and $(b)$ the stationary plate. The narrow gap between the cone and plate contains the sample fluid, which is sheared by rotating the cone. trophoresis for $1 \mathrm{~h}$ at $50 \mathrm{~V}$ and $4 \mathrm{~h}$ at $100 \mathrm{~V}$, protein was fixed in the gels by $10 \%$ acetic acid/10\% isopropanol. The gels were washed for $1 \mathrm{~h}$ in two changes of deionized water, soaked for $1 \mathrm{~h}$ in $0.036 \mathrm{M}$ sodium borate $/ 0.150 \mathrm{M} \mathrm{NaCl}$ containing $1 \mathrm{mg} / \mathrm{ml} \mathrm{BSA}$ (Cohn fraction $\mathrm{V}$, fatty acid free; Sigma Chemical Co., St. Louis, MO), pH 8.0, and incubated for $18 \mathrm{~h}$ at $23^{\circ} \mathrm{C}$ with rabbit ${ }^{125} \mathrm{I}$-antihuman vWF IgG $\left(1 \times 10^{5} \mathrm{cpm} /\right.$ $\mathrm{ml}$ ) in borate $/ \mathrm{NaCl}$, for $48 \mathrm{~h}$ in two changes of $0.5 \mathrm{M} \mathrm{NaCl}$, followed by three changes of $0.15 \mathrm{M} \mathrm{NaCl}$, and then in $2 \%$ glycerol/10\% acetic acid for $1 \mathrm{~h}$. The gels were dried in an oven at $56^{\circ} \mathrm{C}$ for $6 \mathrm{~h}$ and placed with XAR-Omat film (Eastman Kodak Co., Rochester, NY) and Chronex Lightning Plus intensifying screens (E. I. duPont de Nemours and Co., Inc., Wilmington, DE) for $24-48 \mathrm{~h}$ at $-70^{\circ} \mathrm{C}$.

Endothelial cells from human umbilical veins were isolated and grown to confluency in primary culture (19) in $35-\mathrm{mm}$ dishes or glass slides containing medium 199 (Gibco Laboratories, Grand Island, NY) and $20 \%$ fetal calf serum (HyClone Laboratories, Logan, UT) with $3 \%$ penicillin-streptomycin-neomycin and $1 \%$ glutamine. The cells were then washed twice in Dulbecco's phosphate-buffered saline (Gibco Laboratories) and allowed to produce vWF in defined medium (5 $\mu \mathrm{g}$ insulin, 5 $\mu \mathrm{g}$ transferin, medium 199, 0.2\% BSA, 3\% penicillin-streptomycin-neomycin, $1 \%$ glutamine). For shear experiments, endothelial cell culture medium was obtained after 24-61 h of cell incubation in defined medium, when vWF antigen levels were 3-10\% (3-10 U/dl).

For each purification of human vWF multimeric forms, $10 \mathrm{U}$ cryoprecipitate $(\sim 250 \mathrm{ml})$ was thawed at $37^{\circ} \mathrm{C}$, dissolved in $1 / 20$ plasma volume with $55 \mathrm{mM}$ sodium citrate, $\mathrm{pH} 7.4$, and stirred in a $37^{\circ} \mathrm{C}$ waterbath for $30 \mathrm{~min}$. Glycine buffer (2.6 M glycine, $0.3 \mathrm{M} \mathrm{NaCl}, 25 \mathrm{mM}$ Tris, $\mathrm{pH}$ 6.8) was added to a final concentration of $2.0 \mathrm{M}$ glycine (20). After stirring for another hour, the solution was centrifuged at $5,000 \mathrm{~g}$ and $23^{\circ} \mathrm{C}$ for $30 \mathrm{~min}$. Solid $\mathrm{NaCl}$ was added $(90 \mathrm{~g} / 1000 \mathrm{ml}$ of supernatant), and the mixture was stirred for $1 \mathrm{~h}$ at $37^{\circ} \mathrm{C}$ and centrifuged at $20,000 \mathrm{~g}$ and $23^{\circ} \mathrm{C}$ for $30 \mathrm{~min}$. The precipitate was dissolved in $10 \mathrm{ml}$ of $\mathrm{NaCl}$-citrate buffer $(25 \mathrm{mM}$ citric acid, $0.15 \mathrm{M} \mathrm{NaCl}, \mathrm{pH} 6.15)$ at $37^{\circ} \mathrm{C}$. The solution was centrifuged at $1,000 \mathrm{~g}$ for $5 \mathrm{~min}$ to remove the lipid fraction before column purification. It was then applied to a Sepharose $4 \mathrm{~B}$ column $(2.5 \times 50 \mathrm{~cm}$ with a bed volume of $3,000 \mathrm{ml}$; Pharmacia, Inc., Piscataway, $\mathrm{NJ}$ ) and eluted with $\mathrm{NaCl}$-citrate buffer at room temperature. The flow rate was $1 \mathrm{ml} / \mathrm{min}$, and fractions of $1 \mathrm{ml}$ were collected.

\section{Results}

The initiation of shear-induced platelet aggregation in PRP in our system was dependent on the presence of normal plasma vWF multimeric forms (Fig. 2). Platelet vWF multimers, including unusually large forms that may be released from platelet $\alpha$-granules during shear, were relatively unimportant in the aggregation process. Severe vWD platelets with undetectable vWF antigen and multimeric forms aggregated normally in the shear field when they were suspended in normal PPP. In contrast, normal platelets in severe vWD plasma $(<1 \% \mathrm{vWF}$ antigen and undetectable vWF multimers) aggregated only relatively modestly, even after $5 \mathrm{~min}$ of exposure time. The same results were obtained with vWD plasma containing $13 \% \mathrm{vWF}$ antigen but none of the largest plasma vWF forms.

The modest shear-induced increase in the numbers of single platelets in severe vWD PPP (Fig. 2) was due to dispersion of some microaggregates that were present in the platelet/plasma suspensions before application of the shear field.

As mentioned above, relatively large vWF multimeric forms were necessary to initiate shear-induced platelet aggregation. This is demonstrated in Fig. 3. When purified preparations enriched in the largest plasma vWF multimeric forms were added to severe vWD plasma, shear-induced aggregation of normal platelets suspended in this plasma was induced much more effectively than when the platelets were suspended in severe vWD plasma, enriched in relatively smaller vWF forms. 
$\mathbf{A}$

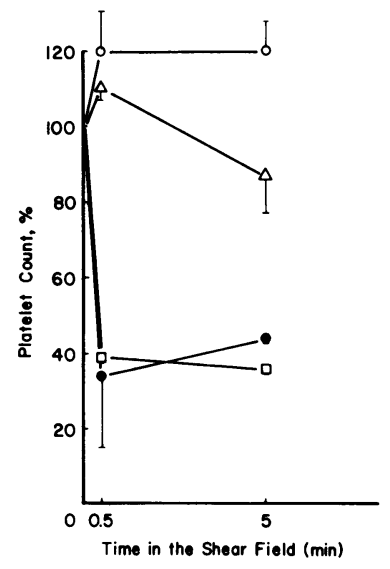

B

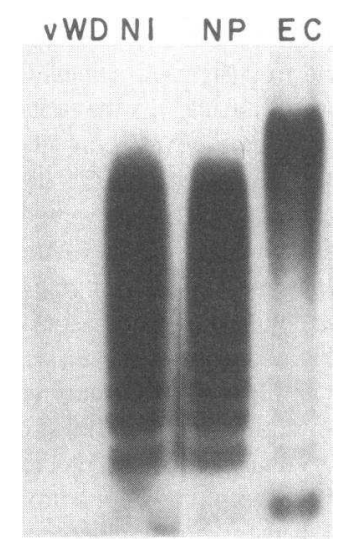

Figure 2. Effect of the presence or absence of vWF on shear stressinduced platelet aggregation. Shear stress was $180 \mathrm{dyn} / \mathrm{cm}^{2}$. Initial platelet counts in the samples before shearing were $366,000-406,000$ / $\mu$ l. As platelets aggregate in the shear field, the percentage of platelets remaining in the samples as single platelets (ordinate) decreases. $(A)$ Extent of aggregation in the samples: $\bullet$, normal platelets in normal PPP; $\square$, severe vWD platelets in normal PPP; $\triangle$, normal platelets in severe vWD PPP; and 0 , severe vWD platelets in severe vWD PPP. $(B) \mathrm{vWF}$ multimeric forms in PPP of vWD and normal (Nl) PPP samples used in $A$. Normal pooled PPP (NP) and cultured human umbilical vein endothelial cell supernatant (EC) samples are shown for comparison.

Fig. 3 also demonstrates that the addition to severe vWD plasma of supernatant from cultured human umbilical vein endothelial cells, which contains unusually large vWF multimeric forms, is 5-15 times more effective (on the basis of comparative vWF antigen levels) in initiating shear-induced aggregation of normal platelets. When endothelial cell supernatant was depleted of $\mathrm{vWF}$ by incubation with monospecific, polyclonal $\mathrm{vWF}$ antibody and Protein-A sepharose, the vWF-depleted endothelial cell supernatant did not support platelet aggregation in the shear field. These experiments indicate that $\mathrm{vWF}$, not some other en-

dothelial cell product, is responsible for supporting shear-induced platelet aggregation.

vWF quantification and multimeric analysis determined that no vWF multimeric forms of any size attached to the viscometer, either in the presence or absence of shear. Shear stress applied for $30 \mathrm{~s}$ or $5 \mathrm{~min}$ did not alter the apparent extent of multimerization of vWF forms in normal plasma, normal whole blood, purified VWF preparations, or endothelial cell supernatant samples (as detected by SDS-gel electrophoresis and autoradiography).

In contrast to the near absence of shear-induced platelet aggregation in severe vWD plasma, normal platelets in afibrinogenemic plasma aggregated almost normally in the shear field (Fig. 4).

The shear-induced aggregation of platelets in citrated whole blood was decreased by $45-60 \%$ in either the absence of vWF or the presence of a monoclonal antibody to the primary platelet vWF receptor, GPIb (Fig. 5). In the presence of a monoclonal antibody to platelet GPIIb and/or GPIIla that inhibits the binding of fibrinogen, fibronectin, thrombospondin, and vWF to the GPIIb/IIIa complex, shear-induced aggregation in whole blood was decreased by $\sim 45 \%$. When a monoclonal antibody to platelet GPIIb and/or GPIIIa complex was added to severe vWD whole blood, shear-induced platelet aggregation was almost completely inhibited. These results indicate that both the binding of vWF multimers to GPIb and the binding of vWF or other proteins to the GPIIb/IIIa complex are required for the shearinduced aggregation of platelets in whole blood.

\section{Discussion}

The initiation of shear-induced aggregation of platelets in citrated plasma and whole blood at ambient temperature is dependent on the presence of the largest plasma vWF multimers. In platelet/ plasma suspensions, this dependence on large vWF forms is nearly absolute.

The fluid shear stresses in our experiments were applied to platelet/plasma suspensions or to whole blood samples that were
$\mathbf{A}$

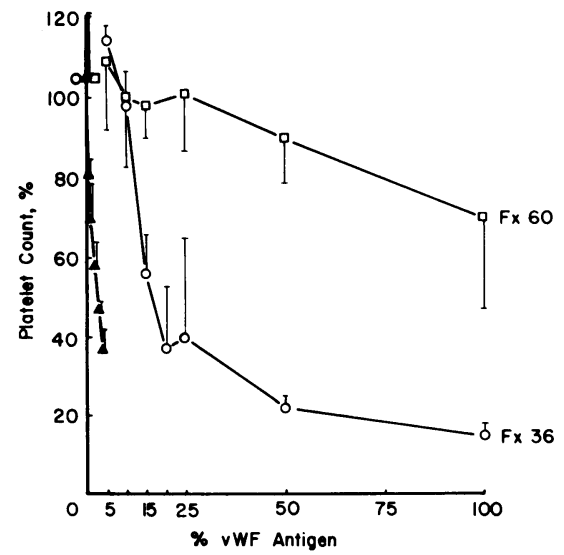

B

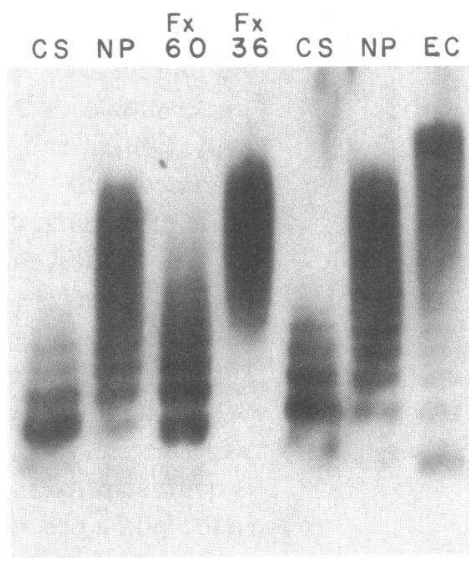

Figure 3. Effect of different vWF multimeric forms on shear stress-induced platelet aggregation in severe vWD PRP. Shear stress was $180 \mathrm{dyn} / \mathrm{cm}^{2}$. Platelets in the severe vWD PRP samples were 304,000-396,000/ $\mu \mathrm{l}$, and $\mathrm{vWF}$ antigen in plasma and platelets was $<1 \%$ of normal. $(A)$ Purified vWF preparations predominantly composed of large (O, fraction $[\mathrm{Fx}] 36)$ or small $(\square$, fraction $[F x] 60)$ vWF multimeric forms were added to the severe vWD PRP samples before shearing in the antigen concentrations indicated. The fraction numbers refer to $V_{0}(36)$ or $V_{\mathrm{I}}(60)$ fractions from a Sepharose 4B column in the last step of the vWF purification process described in Methods. In other experiments, vWF multimers that include the unusually large forms synthesized and secreted by endothelial cells in a defined, serum-free medium were added to the suspension of normal platelets in severe vWD plasma before shearing $(\Delta)$ to produce the vWF antigen levels indicated on the abscissa. $(B)$ The gel shows the vWF multimeric patterns in PPP samples prepared from severe vWD PRP to which fraction 36 or fraction 60 had been added before shearing. vWF multimers in normal pooled PPP (NP), the cryosupernatant (CS) fraction of normal plasma (i.e., plasma after the removal of cryoprecipitate), and the supernatant of normal human endothelial cells cultured in serum-free, defined medium (EC) are shown for comparison. 


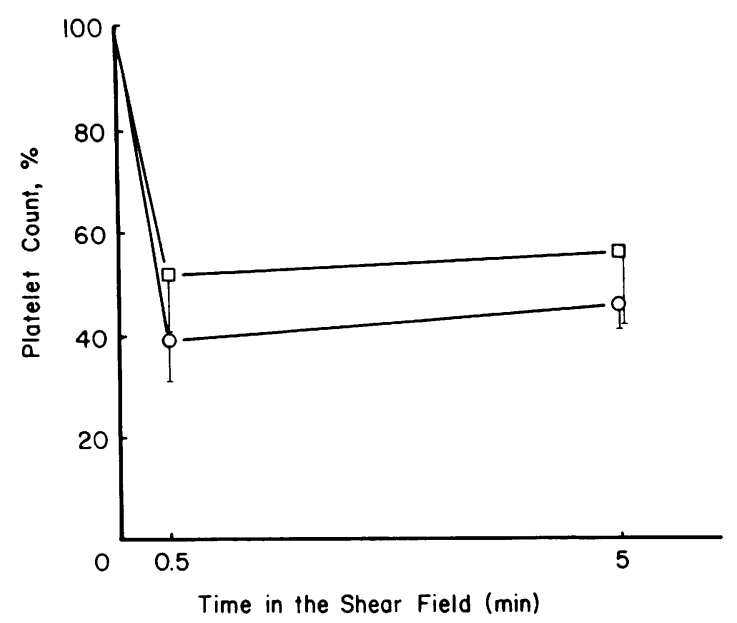

Figure 4. Effects of fibrinogen on shear stress-induced platelet aggregation. Normal platelets $(255,000-515,000 / \mu l)$ were suspended in 0 , normal plasma, or $\square$, plasma from a patient with congenital afibrinogenemia. Shear stress was $180 \mathrm{dyn} / \mathrm{cm}^{2}$. vWF antigen levels in the afibrinogenemic plasma samples before the addition of platelets were $57-81 \%$, and multimer patterns were indistinguishable from normal PPP.

placed between the rotating cone and stationary plate of a rotational viscometer. These shear stresses promoted plateletplatelet collisions in PRP and cell-cell collisions in whole blood, with resulting platelet aggregation. At the same level of shear stress, more platelet-platelet collisions are expected per unit of time in PRP than in whole blood, and this contributes to the more extensive platelet aggregation at $180 \mathrm{dyn} / \mathrm{cm}^{2}$ in PRP than in whole blood. It has been demonstrated previously that platelet

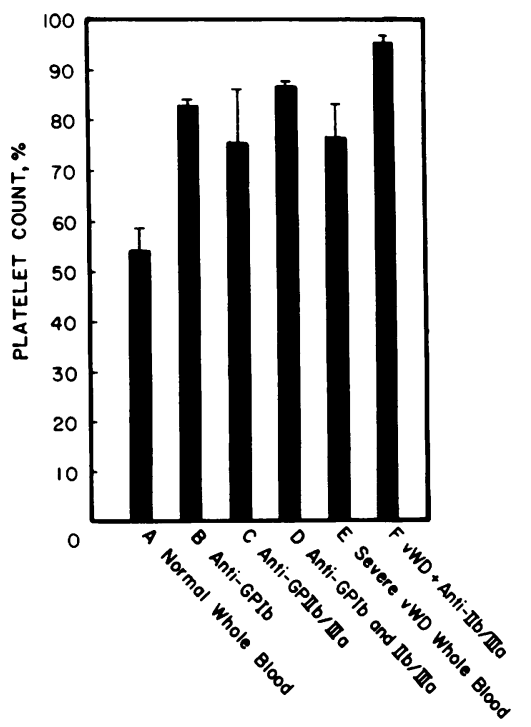

Figure 5. Effect of vWF on shear stress-induced platelet aggregation in whole blood. The samples were: blood from three normal individuals $(A)$; normal blood preincubated with anti-GPIb $(B)$ or anti-GPIIb/IIIa $(C)$ monoclonal antibody, or with both monoclonal antibodies $(D)$; blood from a patient with severe vWD $(<1 \% \mathrm{vWF}$ antigen in plasma and platelets, $E$ ); or severe vWD blood preincubated with anti-GPIIb/ IIIa monoclonal antibody. In these blood samples, hematocrit values were $34-40 \%$, platelets were $300,000-500,000 / \mu 1$, and white and differential counts were normal. Shear stress was $180 \mathrm{dyn} / \mathrm{cm}^{2}$ for $30 \mathrm{~s}$. aggregation in this instrument is independent of any minimal platelet-surface interactions that may occur $(7,8,12)$.

In the present studies, we detected no adsorption of vWF onto the surface of the viscometer or alteration in vWF multimeric structure by the shear stresses imparted to plasma, platelet/ plasma suspensions, or whole blood samples. Consequently, it is unlikely that the shear stress-induced platelet aggregation observed was a result of the adsorption of large vWF multimers to the viscometer surface, subsequent platelet adherence, release of ADP and other granular contents, and aggregation.

The shear-induced aggregation of platelets in plasma described in this report is unique in that it is initiated by physical forces in the presence of large vWF multimeric forms, including the largest vWF forms present in normal plasma. Unlike the other types of vWF-mediated aggregation extensively studied mostly with nephelometry and stirred platelet suspensions in plasma or plasma components (21), shear-induced aggregation of platelets initiated by vWF does not require the addition of exogenous ristocetin or other polycations or chemical desialation of vWF molecules $(22,23)$. Since the shear forces cause no detectable change in vWF multimeric structure, we infer that shearinduced platelet aggregation initiated by vWF is a result of increased exposure or an alteration in structure of platelet receptors for large vWF multimeric forms by the applied fluid shear forces. This conclusion is supported by our observations that monoclonal antibodies' blockade of the known platelet surface receptors for vWF, i.e., GPIb $(24,25)$ and the GPIIb/IIIa complex $(22,23,26)$, interfere with the shear-induced aggregation of platelets in whole blood.

Suppression by aspirin of ADP release from platelets in normal PRP has little effect on shear-induced aggregation (27). This observation makes it unlikely that ADP released from sheared platelets in PRP is involved in altering the exposure of platelet surface receptors and inducing the attachment of large plasma vWF forms. Furthermore, other studies on Bernard-Soulier and thrombasthenic PRP (28) indicate that ADP release in the shear field is not sufficient to result in platelet aggregation in the absence of either platelet GPIb or the GPIIb/IIIa complex. This latter work provides additional evidence for the primary importance of the attachment of large vWF multimeric forms to platelet glycoprotein receptors in shear-induced aggregation.

Our results presented here also indicate that the near absence of fibrinogen in afibrinogenemic plasma has little effect on shearinduced platelet aggregation when plasma vWF concentrations are within the normal range. These findings are compatible with another recent report of the interaction between vWF and GPIIb/ IIIa in patients with afibrinogenemia (26).

Our data on shear-induced platelet aggregation suggest the following sequence of events: perturbation by shear forces of the structure or exposure of platelet surface vWF receptors; attachment of large vWF multimeric forms to GPIb and possibly to the GPIIb/IIIa complex; and platelet aggregation. Our experiments with whole blood suggest that some other protein, perhaps fibrinogen or fibronectin, might also be induced to bind to the platelet GPIIb/IIIa complex and potentiate aggregation under the influence of the shear field or ADP released from erythrocytes or platelets $(11,13)$.

Another observation of potential importance that is derived from these studies relates to the unusually large vWF multimeric forms synthesized and secreted by human endothelial cells (16). We found that human umbilical vein endothelial cell culture medium, which contains unusually large vWF multimeric forms, 
is 5-15 times more effective per vWF antigen unit in supporting the initiation of platelet aggregation by shear forces than the largest vWF multimers purified from the cryoprecipitate fraction of normal plasma. Other work indicates that human endothelial cells have the capacity to synthesize unusually large vWF multimers in vivo (16) and package them in Weibel-Palade bodies $(29,30)$. As they are secreted from endothelial cells, the unusually large forms derived from endothelial cells are normally processed by a component in the cryosupernatant fraction of normal plasma to the somewhat smaller vWF forms present in normal circulation $(16,31,32)$. When this processing does not occur on the abluminal side of the endothelial cell, unusually large vWF multimers become part of the subendothelium (33). The experiments reported in this paper suggest that unusually large vWF multimeric forms interact with platelets more effectively than the largest plasma vWF forms. This suggestion is a possible explanation for the more effective binding of platelets to subendothelial vWF multimers, compared with relatively smaller plasma vWF forms, during normal hemostasis.

High levels of fluid shear stress in the arterial microcirculation, such as those from spasm or stenosis of arterioles, may modify platelet surfaces and alter or increase the exposure of platelet membrane receptors for vWF. Large plasma vWF forms may then bind to platelets and initiate platelet aggregation.

Our studies also suggest the possibility that in the presence of high shear stress levels the transient release of small quantities of unprocessed unusually large vWF multimeric forms into the regional circulation may lead to platelet aggregation. Unusually large vWF multimers may be predominantly contained within endothelial cell Weibel-Palade bodies $(29,30)$. Therefore, it is possible to propose at least three conditions in which unusually large vWF multimeric forms derived from endothelial cells might appear in the regional blood. One of these conditions is intense local stimulation of endothelial cell secretion of the contents of Weibel-Palade bodies, which overwhelms the process on endothelial cell surfaces $(31,32)$ that normally converts unusually large vWF multimers to the somewhat smaller circulating forms. A second hypothetical condition is local damage to endothelial cells of sufficient severity to result in the disruption of WeibelPalade bodies, as well as endothelial membranes and the associated converting process for unusually large vWF multimers. A third putative condition is damage to local endothelial cells that is more modest in extent, resulting in interference with local processing of unusually large vWF multimers as they are secreted by otherwise intact endothelial cells. A problem analogous to this latter defect apparently occurs in systemic form in some patients with chronic relapsing thrombotic thrombocytopenic purpura, the paradigm arterial thrombotic disorder $(16,31)$.

\section{Acknowledgments}

We appreciate the additional technical contributions of Ms. Marcella Estrella and the excellent secretarial assistance provided by Ms. Andrea K. Bethel.

This work was supported by the National Institutes of Health grants 3PO HL 13262, R01 HL 35387, and R01 H1 18584.

\section{References}

1. Back, C. H., J. R. Radbill, and D. W. Crawford. 1977. Analysis of pulsatile viscous blood flow through diseased coronary arteries of man. J. Biomech. 10:339-353.
2. Lipowski, H. H., S. Usani, and S. Chien. 1980. In vivo measurements of "apparent viscosity" and microvessel hematocrit in the mesentery of the cat. Microvasc. Res. 19:297-319.

3. Turitto, V. T. 1982. Blood viscosity, mass transport, and thrombogenesis. Prog. Hemostasis Thromb. 6:139-177.

4. Ross, R. 1986. The pathogenesis of atherosclerosis: an update. $N$. Engl. J. Med. 314:486-500.

5. Brown, C. H., L. B. Leverett, C. N. Lewis, C. P. Alfrey, and J. D. Hellums. 1975. Morphological, biochemical and functional changes in human platelets subjected to shear stress. J. Lab. Clin. Med. 86:462471.

6. Hung, T. C., R. M. Hochmuth, J. H. Joist, and S. P. Sutera. 1976. Shear-induced aggregation and lysis of platelets. Trans. Am. Soc. Artif. Intern. Organs. 22:285-291.

7. Anderson, G. H., J. D. Hellums, J. L. Moake, and C. P. Alfrey. 1978. Platelet lysis and aggregation in shear fields. Blood Cells (Berl.). 4:499-507.

8. Anderson, G. H., J. D. Hellums, J. L. Moake, and C. P. Alfrey. 1978. Platelets response to shear stress: changes in serotonin uptake, serotonin release, and ADP induced aggregation. Thromb. Res. 13:10391047.

9. Yung, W., and M. M. Frojmovic. 1982. Platelet aggregation in laminar flow-ADP concentration, time and shear rate dependence. Thromb. Res. 28:361-377.

10. Moritz, M. W., R. C. Reimers, R. K. Baker, S. P. Sutera, and J. H. Joist. 1983. Role of cytoplasmic and releasable ADP in platelet aggregation induced by laminar shear stress. J. Lab. Clin. Med. 101: 537-544.

11. Jen, C. J., and L. V. McIntire. 1984. Characteristics of shearinduced aggregation in whole blood. J. Lab. Clin. Med. 103:115-124.

12. Belval, T. K., J. D. Hellums, and R. T. Solis. 1984. The kinetics of platelet aggregation induced by fluid-shearing stress. Microvasc. Res. 28:279-288.

13. Aursnes, I., K. Gjesdal, and U. Abildgaard. 1981. Platelet aggregation induced by ADP from unsheared erythrocytes at physiological $\mathrm{Ca}^{++}$concentration. Br. J. Haematol. 47:149-152.

14. Turitto, V. T., H. J. Weiss, and H. R. Baumgartner. 1984. Platelet interaction with rabbit subendothelium in von Willebrand disease: altered thrombus formation distinct from defective platelet adhesion. J. Clin. Invest. 74:1730-1741.

15. Joist, J. H., E. J. Bauman, M. Speer, and S. P. Sutera. 1985. Role of platelet surface interaction in fluid shear-induced platelet aggregation. Thromb. Haemostasis. 54:109. (Abstr.)

16. Moake, J. L., C. K. Rudy, J. H. Troll, M. J. Weinstein, N. M. Colannino, J. Azocar, R. H. Seder, S. L. Hong, and D. Deykin. 1982. Unusually large plasma factor VIII: von Willebrand factor multimers in chronic relapsing thrombotic thrombocytopenic purpura. New Engl. J. Med. 307:1432-1435.

17. Coller, B. S., E. I. Peerschke, L. E. Scudder, and C. A. Sullivan. 1983. Studies with a murine monoclonal antibody that abolishes ristocetin induced binding of von Willebrand factor to platelets: additional evidence in support of GPIb as a platelet receptor for von Willebrand factor. Blood. 61:99-110.

18. Coller, B. S., E. I. Peerschke, L. E. Scudder, and C. A. Sullivan. 1983. A murine monoclonal antibody that completely blocks the binding of fibrinogen to platelets produces a thrombasthenic-like state in normal platelets and binds to glycoproteins IIb and/or IIIa. J. Clin. Invest. 72: 325-338.

19. Hong, S. L. 1980. Effect of bradykinin and thrombin on prostacyclin synthesis in endothelial cells from calf and pig aorta and human umbilical cord vein. Thromb. Res. 18:787-795.

20. Thorell, L., and B. Blomback. 1984. Purification of the factor VIII complex. Thromb. Res. 35:431-450.

21. Zimmerman, T. S., and Z. M. Ruggeri. 1983. von Willebrand's disease. Clin. Haematol. 12:175-200.

22. de Marco, L., A. Girolami, S. Russell, and Z. M. Ruggeri. 1985. Interaction of asialo von Willebrand factor with glycoprotein Ib induces 
fibrinogen binding to the glycoprotein IIb/IIIa complex and mediates platelet aggregation. J. Clin. Invest. 75:1198-1203.

23. Gralnick, H. R., S. B. Williams, and B. S. Coller. 1985. Asialo von Willebrand factor interactions with platelets. Interdependence of glycoproteins $\mathrm{Ib}$ and IIb/IIIa for binding and aggregation. J. Clin. Invest. 75:19-25.

24. Nurden, A. T., and J. P. Caen. 1979. The different glycoprotein abnormalities in thrombasthenic and Bernard-Soulier platelets. Semin. Hematol. 16:234-250.

25. Moake, J. L., J. D. Olson, J. H. Troll, S. S. Tang, T. Funicella, and D. M. Peterson. 1980. Binding of radioiodinated human von Willebrand factor to Bernard-Soulier, thrombasthenic and von Willebrand's disease platelets. Thromb. Res. 19:21-27.

26. de Marco, L., A. Girolami, T. S. Zimmerman, and Z. M. Ruggeri. 1986. von Willebrand factor interaction with the glycoprotein IIb/IIIa complex: its role in platelet function as demonstrated in patients with congenital afibrinogenemia. J. Clin. Invest. 77:1272-1277.

27. Hardwick, R. A., J. D. Hellums, D. M. Peterson, and J. L. Moake. 1981. The effects of ASA, $\mathrm{PGE}_{1}, \mathrm{PGI}_{2}$, and theophylline on the response of platelets subjected to shear stress. Blood. 58:678-681.
28. Peterson, D. M., N. A. Stathopoulos, J. D. Hellums, and J. L. Moake. 1986. Irreversible shear induced platelet aggregation requires von Willebrand factor and platelet membrane glycoproteins Ib and IIb/ IIIa. Clin. Res. 34:662A. (Abstr.)

29. Wagner, D. D., J. B. Olmsted, and V. J. Marder. 1982. Immunolocalization of von Willebrand protein in Weibel-Palade bodies of human endothelial cells. J. Cell Biol. 95:355-360.

30. Sporn, L. A., V. J. Marder, and D. D. Wagner. 1986. Inducible secretion of large, biologically potent von Willebrand factor multimers. Cell. 46:185-190.

31. Moake, J. L., J. J. Byrnes, J. H. Troll, C. K. Rudy, S. L. Hong, M. J. Weinstein, and N. M. Colannino. 1985. Effects of fresh frozen plasma and its cryosupernatant fraction on von Willebrand factor multimer forms in chronic relapsing thrombotic thrombocytopenic purpura. Blood. 65:1232-1236.

32. Frangos, J., J. L. Moake, L. Nolasco, and L. McIntire. 1986. Evidence for an unusually large factor VIII: vWF depolymerase in normal plasma cryosupernatant. Clin. Res. 34:656A. (Abstr.)

33. Hong, S. L., M. J. Weinstein, and J. L. Moake. 1983. von Willebrand factor multimer forms produced by human endothelial cells. Blood. 62(Suppl. 1):286a. (Abstr.) 